\title{
O Paraná: Uma Visão de Conjunto
}

\author{
Pedro Calil Padis *
}

Neste artigo procuraremos observar a evolução do crescimento populacional do Paraná e identificar as características principais de sua economia, bem como auscultar que perspectivas existem para o estado.

Comecemos com a evolução demográfica do estado do Paraná. Esta se deu sempre de forma bastante rápida, em ritmo sempre maior que o do conjunto do pals. Com efeito, nos três quartos de século compreendidos en-tre 1854 e 1930, enquanto a população brasileira se multiplicava cinca vêzes, a paranaense aumentava em proporção quase três vêzes superior e, por essa razão, dobrava cada dezoito anos.

Entretanto, a partir da segunda metade dos anos trinta, quando dos grandes movimentos ocupacionais da regiāo norte $e$, mais tarde, a sudoeste, o Paraná foi palco de um crescimento populacional de proporções até então desconhecidas no país; entre 1920 e 1960, a população paranaense se multiplicou 6,2 vezes, enquanto que a do conjunto do pais aumentava, apenas, 2,3 vézes.

Os dados relacionados no quadro 1 mostram como evolulram essas duas populaçōes.

* Ex-professor do Departamento de Clénclas Soclais da Escola de Administraçăo de Empressas de Săo Paulo, da Fundaçăo Getúllo Vargas, atualmente na Facuidade de Direlto e Clénclas Económicas da Universidade de Paris.

R. Adm. Emp., Rlo de Janeiro,
Como se pode observar, entre 1940 e 1950 , o crescimento relativo ocorrido foi de $71,12 \%$, o mais alto entre os estados brasileiros, 1 duas vêzes superior ao do conjunto nacional. Confirmam-no as taxas médlas geométricas anuais de crescimento, de $5,62 \%$ e $2,41 \%$, respectivamente, para o Paraná e Brasil.

No decênio seguinte (entre 1950 e 1960), o crescimento relativo observado na população paranaense foi de $102,21 \%$ - ainda uma vez, o maior de todo o país - enquanto que o da população brasileira não ia além dos $36,6 \%$. E assim, a população paranaense crescia novamente a um ritmo quase trés vêzes superior ao do conjunto do pals, isto é, a uma taxa média geométrica anual de $7,17 \%$, em contrapartida aos $3,1 \%$ para o Brasil. Portanto, se até 1920 a população paranaense dobrou a cada dezoito anos, ao ritmo em que se processou esta evolução entre 1940 e 1950, o teria feito em apenas 14 anos, e na década seguinte, menos de dez teriam sido necessários. . Prosseguindo, pois, os incrementos demográficos verificados fizeram no Paraná um estado densamente povoado, relativamente ao conjunto do país, já que enquanto, em 1960, no Brasil existiam apenas 8,4 habitantes por

1 O crescimento relativo da populaçăo paranaense só fol superado levemente pelo da populaçto radicada na zona litiglosa da serra dos Aimorés.

11(1): $\quad 35-50$

Jan./Mar. 1071 
Quadro 1: Populaçăo Paranaense em Relaçăo à do Brasil 1920/1960

$\begin{array}{lcrc}\text { Censos } & \text { Brasil } & \text { Parand } & \text { PR/BR \% } \\ 1920 & 30.635 .605 & 685.711 & 2,24 \\ 1940 & 41.236 .315 & 1.236 .276 & 3,00 \\ 1950 & 51.944 .397 & 2.115 .547 & 4,07 \\ 1960 & 70.967 .185 & 4.277 .763 & 6,03\end{array}$

Fonte: IBGE. Censos demográficos.

quilômetro quadrado, no Paraná essa relação atingia nada menos que 21,49.

Evidentemente, essas cifras, expressões médias do conjunto do estado, não refletem, exatamente, as diferentes regiōes. 0 considerável aumento populacional da década dos anos quarenta se deveu, quase que ùnicamente, aos grandes fluxos migratórios em direção ao norte do estado. Na década seguinte, porém, embora os movimentos populacionais dirigidos para essa região continuassem intensos, o incremento da população se deu também graças às migrações em demanda do sudoeste.

Interessante e oportuno seria um estudo comparativo da densidade populacional das trés grandes regiōes do estado - Paraná Velho, norte e sudoeste. Mas, já tendo decorrido uma década desde o último censo, os dados disponíveis não expressam, nem de longe, a realidade presente, lembrados sobretudo de que é relativamente recente o fenómeno de povoamento do sudoeste e que sua intensificação se deu, exatamente, nesta última década.

Apesar disso, algumas afirmaçőes se podem fazer sem grande risco de êrro.

A primeira delas $e$ a de que a atual densidade demográfica média do estado bastante superior à registrada uma década atrás, tendo aumentado a desproporção entre a média nacional e a estadual.

Entretanto, pode-se afirmar também, com boa dose de certeza, que na última década o incremento populacional do Paraná deve ter sido proporcionalmente inferior ao ocorrido no decênio dos cinqüenta, uma vez que o fluxo tem direção ao sudoeste insuficientemente compensatória para manter as mesmas taxas de crescimento do decénio anterior. $E$ mais, de agora em diante - quando poucas terras novas ainda existem para ser ocupadas certamente haverá uma queda considerável nas taxas de incremento populacional, pois os acréscimos demográficos provocados por migrações serão certamente menos volumosos. Hoje, Eles ocorrem mais nitidamente em Mato Grosso e Goiás, estados para os quais se deslocou a fronteira agrícola. Portanto, a taxa de crescimento da população paranaense, neste próximo decénio, certamente chegará bem próxima - ainda que possivelmente um pouco maior - da nacional, pois que o incremento da população do estado será, cada vez mais, devido ao crescimento vegetativo.

Mas, voltemos ao presente. A considerável expansão demográfica ocorrida nas últimas décadas, no Paraná, ainda nos apresenta alguns outros aspectos bastante interessantes, quanto a alocação populacional. Observemos o seguinte quadro:

Quadro 2. Paraná: Populaçăo Rural e Urbana em 1.000 Pessoas

\begin{tabular}{rrrrr} 
Ano & Urbana & \multicolumn{1}{c}{$\%$} & \multicolumn{1}{c}{ Rural } & \multicolumn{1}{c}{$\%$} \\
1940 & 302 & 24,45 & 934 & 75,55 \\
1950 & 528 & 24,97 & 1.387 & 75,03 \\
1960 & 1.328 & 31,04 & 2.950 & 68,76
\end{tabular}

Fonte: IBGE. Censos demográficos.

Por ele, pode-se perceber claramente que o grande aumento populacional da década dos anos quarenta não alterou práticamente em nada a distribuição relativa da população entre os setores urbano e rural, apesar de o número de cidades ter passado de 49 , em 1940, a 80, em 1950. Na década seguinte, entretanto, essa composição relativa foi alterada, embora ainda não substancialmente, conquanto, entre 1950 e 1960, o número de municípios do estado tivesse mais que duplicado, . pois chegou a 162.

A primeira vista, poder-se-ia atribuir êsse aumento de núcleos urbanos à evidéncia de um rápido processo de urbanização que 
estaria ocorrendo no estado. Entretanto, essa conclusão é, se não totalmente falsa, pelo menos discutivel, pois os municípios surgidos foram decorrência da colonização rápida de uma vasta área, distante dos núcleos urbanos jà existentes e carente, portanto, de algumas atividades do setor terciário. As pequenas vilas que surgiram eram apenas um ponto de reunião dos produtores agrícolas. Pode-se dizer, em conseqüencia, que no Paraná o setor primário foi fortemente urbanizador. 2 Não se pode esquecer, ainda nesse aspecto, o papel importante desempenhado pela Companhia de Terras do Norte do Paraná, pois foi graças ao seu planejamento que muitas cidades - umas próximas às outras - surgiram na região norte. Mas não resta dúvida de que muitas dessas pequenas vilas criadas se constituiam em núcleos proto-urbanos - pequenos aglomerados de casas de madeira ao longo da estrada, onde pràticamente tudo que caracteriza uma cidade, mesmo pequena, inexistia. Contudo, as exigências legais, que se consubstanciavam fundamentalmente no quantum de impostos passivel de ser arrecadado, permitiam que fàcilmente fóssem elevados à categoria de municípios, dado o volume de produção agrícola obtido.

O que se afirma ganha consistência se se observa mais o seguinte: em 1950, apenas uma quarta parte da população do estado era urbana, e dèsse total, quase a sua metade $(46,6 \%)$ estava concentrada nas três únicas cidades com mais de vinte mil habitantes. Em 1960 , o número de cidades dêsse porte já ascendia a oito, e nedas se abrigavam $53,3 \%$ da população urbana. Por outro lado, o número de pequenas cidades cresceu consideràvelmente ao periodo compreendido entre os dois últimos censos. Assim, em 1950, o número de cidades com menos de cinco mil habitantes

2 A propósito ver: Comminos, Constantino. Alguns nspectos popuiacionais do Paraná. Revista paranaense de desenvolvimento. Curitiba, (3): 47-57. nov. de 1967. Aspectos demográficos da urbanizaçăo do Paraná. neviata paranaence de decenvolvimento, Curitiba, (5): 47-57, mar./abr. de 1968.

Janeiro/Março 1971 não ia além de 61, enquanto em 1960, chegava à casa dos 114. Mas se elas eram auspiciosas em número, o mesmo não se dava com sua população, pois, enquanto em $195025,6 \%$ da população urbana estava ali radicado, em 1960 essa cifra atingia apenas os $20,4 \%$. Por outro lado, enquanto a população média das cidades com mais de 20.000 passava dos $71.382 \mathrm{em}$ 1950 para 78.872 em 1960, a daquelas cujo número de habitantes varia entre 2.001 e 5.000 , mudava-se nesse periodo apenas de 3.102 para 3.157.

E já agora, no decénio dos anos sessenta, o estado do Paraná voltou a sofrer nóvo e grande aumento no número de cidades, que chegam presentemente a 288. Considerável parte désse aumento foi devido ao fenómeno do povoamento sudoeste, como já se mostrou, embora na região norte também se tenham desenvolvido vários désses núcleos.

De um modo geral, pode-se dizer que muitas das cidades, criadas durante a última década, o foram da mesma forma que muitas outras em periodos anteriores, isto é, embora não dispusessem de requisitos ou qualificações caracterizadores de um núcleo urbano, por detentoras de um volume de produção e renda, podiam, pelo menos legalmente, pleitear elevação à categoria de cidades. Por outro lado, também nesse último decénio, se acentuou o processo de concentração populacional nos centros urbanos maiores. Embora não seja fácil provar o que se diz, por falta de dados informativos oficiais - o censo de 1970 está apenas no coméço - a evidência do que se afirma póde ser constatada pela observação local. Além disto, embora com menos segurança, pode-se também afirmar que, nesse período, a distribuição da população entre o setor urbano e rural se alterou favoràvelmente ao primeiro, o que vale dizer que o processo urbanizador se acentuou.

Em resumo, pode-se dizer que, entre 1940 e 1970, o estado do Paraná sofreu radical transformação em suas feições. Aquela época, a maior parte de seu território ainda 
estava por ser ocupada e a expressão relativa da sua população era bastante pequena. Em razăo dos grandes movimentos ocupacionais organizados, especialmente ao norte do estado, pela Companhia de Terras e na região sudoeste, e, do deslocamento da fronteira agricola do sul do país em direção a essas duas regiōes, o estado se apresenta atualmente com poucas terras a serem ocupadas e com uma população que o coloca entre os mais populosos da federaçāo. ${ }^{3}$

Nesse mesmo período, a significação econômica do estado do Paraná no conjunto do país, de certa forma, féz paralelo com seu crescimento demográfico. Assim é que, de 1939 a 1967, a renda interna do estado, a preços correntes, multipliçava-se 3.195 vêzes, enquanto que, a do Brasil, no mesmo periodo, 1.465 vêzes; o que quer dizer que a renda do estado conhecia um ritmo mais que duas vêzes superior ao do país.

Pela observação dos dados relacionados ño anexo 3 , vê-se uma clara tendéncia crescente na participação relativa do estado na renda nacional, de forma a passar dos $3 \%$ em 1939 para os 6,54\% em 1967. Entretanto, não obstante a tendência ser sempre ascendente, anos houve de redução dessa participação relativa. Êsse fenômeno é mais notório nos anos de 1954, 1956, 1963 e 1964 e alcança explicação extremamente fácil. Como já se disse, e nunca é demais repetir, o café assumiu uma importância considerável dentro da economia do estado e nos anos imediatamente anteriores aos acima referidos, os cafèzais

3 Em 1960, o Paraná era o qulnto estado mals populoso do Brasil, precedido apenas por Săo Paulo, Minas Gerais, Bahia o Rlo Grande do Sul. E bastante possivel que atualmente ele se coloque em terceiro lugar, ultrapassando, assim, Bahia - Rlo Grande do Sul, que, na última década, sofreram intensos movimentos emigratórios.

4 Apesar da analise que se segue ser feita a partir de dados calculados pela Fundaçăo Getúlio Vargas, chama-se atençăo para o seguinte: a) o ano-base dos dados relativos à renda é 1953, enquanto que o do produto real e 1949 ; b) recentemente foram recalculados os dados relativos à renda. Entretanto, o mesmo năo ocorreu quanto aos do produto real. paranaenses foram duramente castigados pelos efeitos das geadas. Por essa razão, baixada a produção física de café, os efeitos sôbre a renda se fizeram sentir de forma considerável.

Aqui cabe uma outra observação. Apesar do considerável aumento da renda estadual, ela não expressa a realidade do esfôrço produtivo do estado no periodo considerado. O que se diz, torna-se bastante claro se se comparam as participações do estado na renda e no produto real nacionais. ${ }^{4}$

Embora não existam dados apurados para todo o periodo, os disponíveis e relacionados no anexo 2 são suficientes para se confirmar o que se diz.

Com efeito, até 1953/54 as participaçóes relativas da renda e do produto real estaduais no conjunto do país evoluíram mais ou menos paralelamente. Entretanto, a partir dal a participação do produto real cresce grandemente, enquanto a da renda conhece progressão muito mais lenta. Também aqui a justificativa é simples e sem mistérios. A partir de 1953, dado a politica cambial adotada e a nova situaçăo internacional do café, em razão do Acôrdo Internacional do Café, os preços désse produto começaram a entrar em queda, enquanto o Paraná fazia crescer grandemente a sua produção. Com efeito, êsse estado passou a ter uma remuneração cada vez menor do seu principal produto, o que repercutiu na elevação de sua renda interna.

Não nos esqueçamos que aqui se trata de problema de preços relativos. Em assim sendo, a evolução de índice geral de preços agricolas - mesmo excluído o café - foi menos favorável que a dos industriais, como já se viu. Sendo o Paraná um estado onde o setor primário ocupa uma posição muito mais destacada que os demais, é óbvio que êsse fenómeno contribui a acentuar a disparidade entre renda e produto real.

O que se afirma ganha intenso significado pela observação do gráfico 1 . 


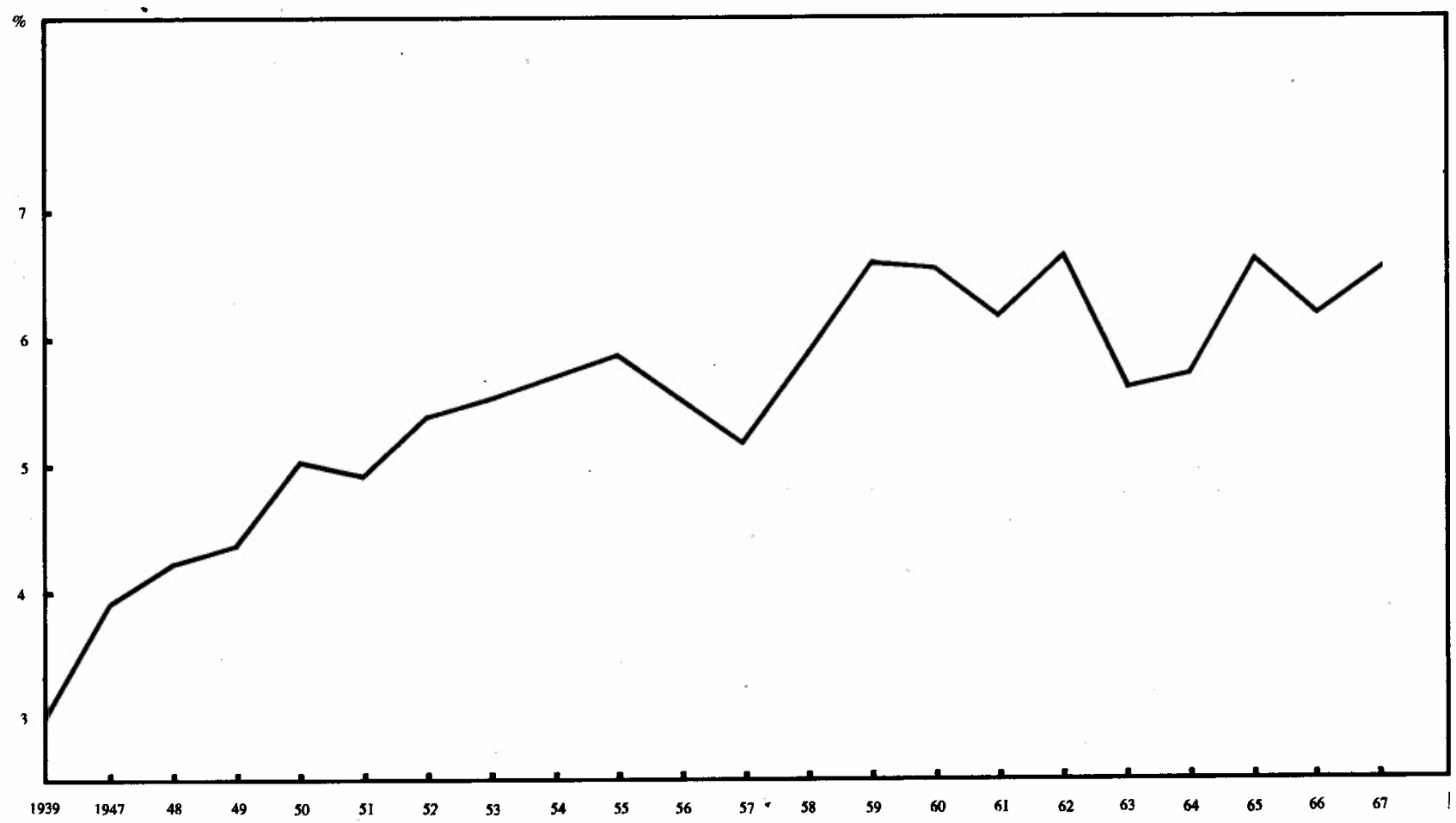

Afirmou-se, logo acima, que entre 1939 e 1967 a renda estadual multiplicara-se em ritmo mais que duas vêzes superior ao da nacional. Entretanto, se se observa evolutivamente a participação de uma na outra, percebe-se que ela cresceu consideràvelmente até 1959. Com efeito, em duas décadas passou de 3 para $6,52 \%$. E mais, èsse crescimento foi contínuo, já que os dois pontos baixos ocorridos em 1954 e 1956 são apenas resultantes de condições acidentais: das geadas que reduziram a safra cafeeira. Entretanto, aos anos posteriores a 1959, e até 1967, o que se tem é uma total estabilidade na participação relativa do estado na geração da renda nacional. Se se lembra, ademais, que data dessa década a ocupação da região sudoeste - - que, em outros têrmos, significa acréscimo de produção e de renda - e mais, que nesse período a econo- mia brasileira, em dura fase, registra baixas taxas de crescimento do produto industrial, é de se concluir que a crise atravessada pelo Paraná - fundamentalmente estado agrícola - em certo sentido é até mais profunda que a do conjunto do país.

Com efeito, se se observam os valôres reais assumidos pela renda gerada no estado, no período compreendido entre 1947 e 1967, percebe-se claramente que até 1959 ela evolui a uma taxa anual acumulada de $9,5 \%$, enquanto que, a partir daí até 1967, essa taxa não vai além dos $3,7 \%$.

Se se considera ainda que a evolução populacional do estado se processa na década dos anos sessenta num ritmo seguramente superior ao do crescimento da renda, é de inferir-se que a renda per capita, a partir de 1959 , deve ter declinado permanentemente. 
Por outro lado, convém observar a composição da renda estadual por setores. Com efeito, como se vê no gráfico 2, a participação relativa do setor primário na renda estadual sofre uma tendência ascensional desde 1939 - quando significava $48,5 \%$ do total - até 1959, quando chega a $55,3 \%$. Entretanto, a partir daí, e apesar da grande participaçăo de 1962, acentua-se-lhe a tendência à queda de expressão. Ao mesmo tempo, e em todo o período, a participação do setor secundário apresenta-se com uma tendência a baixa. Curioso, entretanto, é perceber-se que o setor terciário, a partir de 1959, manifesta um apreciável aumento de importância relativa na composição da renda. Se se detalhar, por ramos de atividade, êste último setor, um outro evento interessante poderá ainda ser notado: a perda de importância relativa das atividades comerciais, enquanto que não menos significativo é o fato de as atividades dos intermediários financeiros multiplicarem quatro vêzes sua im. portância relativa na renda do setor terciário. Cumpre notar que, embora a importáncia relativa dêsse ramo de atividade tivesse crescido sempre, êsse fenómeno mais se evidencia a partir de 1965, como pode sér observado no anexo 4.

Entretanto, por serem muito recentes essas alteraçōes, são temerárias ainda assertivas categóricas sôbre seu possível comportamento futuro. Se se observa o papel assumido pelos diferentes setores ao longo do tempo coberto pelos dados disponíveis, percebe-se que as oscilaçōes são grandes, como pode ser visto no quadro 3.

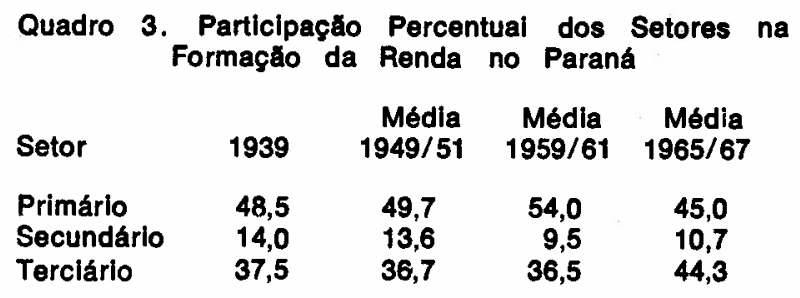

Fonte: Conjuntura economica, (6): 1970.
A observação superficial désses dados poderia levar à conclusão de que o setor primário, após ter conseguido maior significação relativa, estaria, nos últimos anos, cedendo lugar e importância aos outros dois, porque, por um lado, o secundário, após um longo período de decadência, estaria esboçando uma recuperação, enquanto o terciário, durante todo o período, teria mantido um comportamento ascedente.

Entretanto, nada mais temerário do que essa afirmação. Embora se tenha cautelosamente optado por médias trienais que evitassem o efeito de flutuações, não se conseguiu resultado apreciável, porque a atividade econômica do estado é extremamente dependente do café, o qual, por sua vez, sofre forte condicionamento dos efeitos meteorológicos e da política econômica governamental. Assim, o grande aumento da participação relativa do setor primário no triênio 1959/61 pode ser explicado, em parte substancial, pelas grandes safras de 1960 e 1961, enquanto que a baixa verificada em 1965/67 pode igualmente encontrar explicação, pelo menos em boa parte, na erradicação cafeeira e nas pequenas safras de 1965 e 1967, apesar da excelente de 1966.

A exata compreensão das causas determinantes do rápido avanço, primeiro, e da perda de dinamismo, a partir de 1959, da renda gerada pela economia do estado é um fator que elucida grandemente o próprio comportamento da economia, na última década.

Como se viu, no período compreendido entre 1947 e 1959 a renda estadual, a preços constantes, multiplicou-se 3,3 vêzes. Exatamente nesse periodo ocorria a rápida difusão dos cafézais por tôda a região norte do estado - a produção física de café, no Paraná, multiplicava-se cêrca de dezesseis vêzes. A célere multiplicação dos cafèzais paranaenses foi, em grande parte, resultante da expansão da cafeicultura paulista, pois do estado de São Paulo provieram consideráveis contingentes de mãode-obra e algumas parcelas do capital necessário à implantação daquela atividade. E por- 
tanto admissivel afirmar-se que, nesse periodo (1947/59), quando ainda os cafèzais continuavam sua marcha para oeste, uma parte da renda gerada pela cafeicultura era utilizada no estado em reinvestimentos no próprio setor cafeeiro, enquanto outra era retirada para a regiaao industrial do centro do país, especialmente São Paulo. Tão veloz e surpreendente foi a expansão das atividades cafeeiras que os demais ramos de atividades não tiveram condições de acompanhar o seu ritmo, tanto que, no período, os setores secundários e terciários perderam significado relativo na composição da renda estadual.

A principal causa do carreamento de parte da renda gerada no estado, para outros centros do pais, provàvelmente, tem seus fundamentos no seguinte: 0 setor cafeeiro apresentava as maiores vantagens dentro do estado para os investimentos dos capitais acumulados. Dessa forma, nenhuma outra atividade seria suficientemente remunerada e, portanto, atrativa dêsses investimentos. $E$, sendo assim, não se criavam condições para a diversificação da produção. Em conclusão, pois, foi justamente a alta rentabilidade da cafeicultura que limitou, de início, a destinação de recursos para outras atividades. ${ }^{5}$

Entretanto, nos fins da década dos anos cinqũenta, o café pràticamente já havia completado a sua marcha no território paranaense, tendo até ultrapassado os limites da área que Ihe era propicia. A partir de então, as novas inversões nessa atividade foram-se tornando cada vez menores, em relaçăo à renda gerada. Como até essa época o estado se encontrava extremamente carente de infra-estrutura, dado à precariedade das vias de comunicação, à baixíssima produção de energia elétrica, à

5 A propósito ver: CODEPAR. Politica estadual de Investmentos. Curitiba, 1965. Especialmente p. 1-34. PLADEP. Análise da economia paranaense. Curitiba, 1961. p. 2-19.

- Em razăo disso é que se dá o surto industrial de Săo Paulo, a partir da primeira guerra mundial. A propósito, consultar: Luz, Nicia Vilella. A luta pela Industriallzaçăo do Brasll. Săo Paulo, Difusão Européia do Livro, 1961.

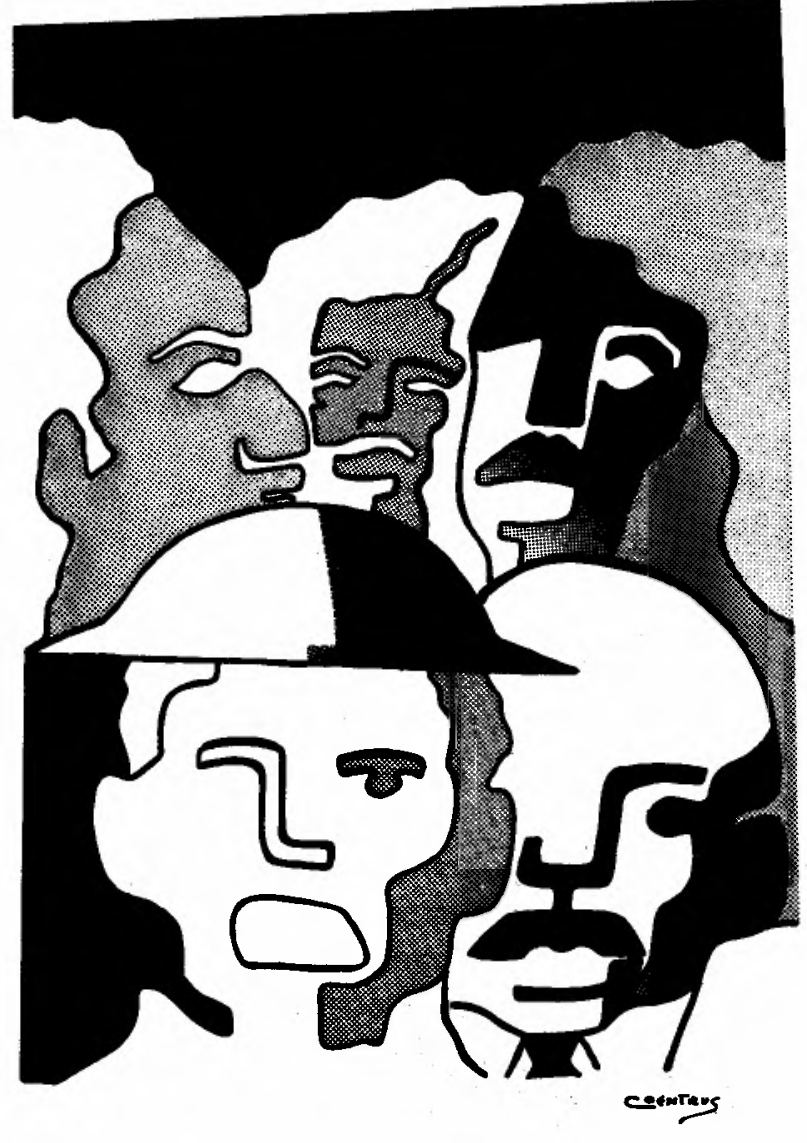

falta de armazéns e silos, ao total desapareIhamento de seus portos e, sobretudo, à insignificância do setor secundário da economia, no momento em que o setor cafeeiro torna-se pouco capaz de absorver novos investimentos, a renda gerada no estado não encontrava muitas alternativas de aplicação. Isso resultou no aparecimento de uma tendência crescente de sua evasão para outros centros do país.

Portanto, a cafeicultura paranaense, ao mesmo tempo em que foi a maior responsável pela rápida transformação econômica registrada no estado, em razão da forma como se desenvolveu e se estruturou, criou barreiras e limitações ao aparecimento de outras atividades económicas, especialmente industriais. Foi assim que, pelos condicionamentos históricos criados, os efeitos multiplicadores dos investimentos realizados fizeram-se sentir apenas num sentido: ampliaram ou criaram condiçóes 
de desenvolvimento às atividades ligadas ou decorrentes da cafeicultura. Como se vê, o café para o Paraná ganhou significado diferente do que teve em São Paulo, pois, enquanto neste estado as poupanças em excesso do necessário para os reinvestimentos na própria agricultura (ou especialmente, cafeicultura) dirigiram-se para os investimentos industriais dentro do próprio estado, ${ }^{6}$ no Paraná isso não ocorreu, pois, à época em que ali se desenvolveu a cafeicultura, a demanda de produtos industrializados já era quase que plenamente satisfeita pela produção paulista. E como de certa forma não se tinha consciéncia da situação do mercado internacional do café, apenas se expandiu a sua produção no estado, dando margem a criação de fluxos de renda voltados para São Paulo.

Se se perguntar por que o poder público estadual não tomou medidas suficientemente eficazes, sanando as deficiências de infra-estrutura e criando condiçōes para os investimentos industriais, a fim de antecipar-se a uma possivel perda de dinamismo da economia local ou mesmo à sua paralisação, uma resposta mais detalhada envolverá vários aspectos.

Em primeiro lugar, deve-se considerar que a expansão ocorrida no estado entre 1930 e 1960 se deu a um ritmo surpreendente. A época da crise de 1929, o Paraná era um estado acanhado, quer no que se refere à parcela ocupada do seu território, quer no que diz respeito à sua situação econômica e financeira. $O$ rápido aumento demográfico e o povoamento de grande parte do território exigiam do estado uma estrutura administrativa ágil e largamente dotada de recursos. Entretanto, a arrecadação estadual dependia sobremaneira dos impostos cobrados sóbre as vendas do café, e como os preços désse produto, de 1953 em diante, evoluíram num ritmo bastante inferior ao do nivel geral de preços, é de se perceber que a arrecadação estadual não cresceu

7 SAGMACS. Plano do desenvolvimento do Paraná. Curitiba, 1963. na rapidez necessária ao volume de investimentos que deveria ter sido feito. $\mathrm{Na}$ verdade, pode-se chegar à conclusão que, durante todo o período de grande produção cafeeira que caracterizou o Paraná, em quase nada o estado aproveitou para implantar uma infraestrutura adequada à manutenção do ritmo de crescimento de sua economia. Esta situação, em muito, faz lembrar os caminhos percorridos pelo Brasil em todo o período dos ciclos de açúcar e da mineração, quando era pouco mais que uma economia periférica da Europa.

O decénio dos anos sessenta, entretanto, foi marcado por ingentes esforços governamentais: inter alia, devem ser destacados aquêles que se dirigiram à supressão das deficiências infra-estruturais e à criação de condições e estímulos à implantação industrial.

Em 1963, um minucioso diagnóstico da situação socioeconómica foi realizado ${ }^{7}$ e várias medidas, sugeridas ao govêrno do estado. A partir dêsse documento, um grande número de estudos setoriais foi feito, com a intenção de permitir que 0 poder público agisse com mais segurança. As medidas concretas tomadas na primeira metade do decênio dos anos sessenta consubstanciaram-se em investimentos equivalentes a $45 \%$ da receita estadual arrecadada no período. Do total dos investimentos feitos, mais de $70 \%$ o foram em infraestrutura, dos quais três quintas partes em rodovias e uma têrça parte em energia elétrica. E obvio que as fontes dos recursos utilizados, em tais casos, não se encontravam tôdas no Tesouro estadual. Porém, désse total, $70 \%$ foram realizados com recursos do estado $e$ o restante através dos cofres da União. Dos efetuados com recursos estaduais, $36 \%$ o foram através de recursos orçamentários e o restante com os fornecidos por órgãos públicos locais. 8

Os resultados désse esfórço foram bastante palpáveis, sobretudo em ralação ao aumento das vias de comunicação que, em quilômetros asfaltados, mais que duplicou na primeira metade do decênio e quadruplicou nos 
últimos 10 anos, e à produçăo de energia elétrica que, em razão do grande potencial instalado na última década, quase quintuplicou. ${ }^{9}$

Foram relevantes ainda os esforços governamentais, em todo o decénio, no que se refere à politica de incentivo à industrialização do estado. Tendo criado a CODEPAR - Companhia de Desenvolvimento Económico do $\mathrm{Pa}$ raná, hoje transformada no Banco de Desenvolvimento Económico do Paraná (BADEP) sob forma de sociedade de economia mista, com a finalidade de "administrar o Fundo de Desenvolvimento Económico" e, entre outras coisas, "promover estudos e projetos de investimentos, bem como aprová-los, quando de sua autoria ou de terceiros e ainda, promover - financiamento daqueles que julgasse convenientes, ${ }^{10} \circ$ govérno do estado financiou cêrca de quinhentas emprésas especialmente industriais, durante a última década.

Dos financiamentos às atividades industriais, deve-se ressaltar que, até 1967, uma quinta parte foi destinada à indústria de extração e elaboração de produtos de origem florestal, ou seja, à produção de conglomerados de madeira, de pasta mecânica e de papel; trinta por cento à indústria de beneficiamento e transformação de produtos da lavoura, donde se destacam as indústrias de óleos vegetais e de café solúvel; e $15 \%$ à indústria de produtos de origem animal, especialmente fri-

8 O governo estadual criou um organismo denominado Fundo de Desenvolvimento. Económlco (Lel no 4.539, de 12 de janeiro de 1962), que, juntamente com o Banco do Estado do Paraná, fol responsável por considerável parte dos investimentos públicos reailzados no estado, em todo o decénio.

Cf. CODEPAR. Política celadual de investimentos. Loc. cit.

Governo do Estado do Paraná. Polittea de desenvolvlmento económico-soclal — programa de inveotimentos, $1963 / 66$.

9 Cf. COPEL. Energla elétrlca no Parand - subsidios so 2 programa estadual de eletriflcacto. 1966.

COPEL. Reiatório de ativldades. 1966/67/68.

10 Lei $n$ ? 4.529, de 12 de janeiro de 1962, art. 10, alíneas $\mathbf{a}, \mathbf{b} \theta \boldsymbol{d}$.

11 Ct. CODEPAR. Relatório de atlvidadea 1965/66/67. gorlficos. Esses trés ramos industriais absorveram mais de três quintas partes de todo o financiamento concedido pela CODEPAR a emprêsas privadas entre 1962 e 1967. ${ }^{11}$

A segunda metade do decénio dos anos sessenta foi igualmente marcada por consideráveis esforços do poder público estadual na sequuência, em linhas gerais, da mesma política do período anterior. Embora ainda não se tenham dados globais sóbre o volume dos investimentos feitos em infra-estrutura $e$ dos financiamentos às atividades econômicas desenvolvidas, esse período foi marcado pela conclusão das importantes obras rodoviárias, pelo alargamento da rêde de armazéns e silos do estado, pelo reaparelhamento dos portos de Antonina e Paranaguá, por maciços investimentos em educação etc.

Aqui cabem, com tôda propriedade, umas perguntas: por que, apesar dêsse esfórço, o setor industrial do estado do Paraná não conseguiu tornar-se mais dinâmico e mais significativo? Por que, exatamente no período em que mais investimentos foram feitos no setor industrial e em infra-estrutura, mais se evidenciaram as dificuldades da industrialização do estado? E por que, exatamente nesse período, o crescimento económico do estado perdeu considerável dinamismo, passando a dar-se mais lentamente?

A resposta a estas indagações é bastante complexa $e$, apenas ela, justificaria todo um estudo. Entretanto, procuraremos pelo menos assinalar alguns aspectos que nos parecem fundamentais.

1. Durante a maior parte da sua história o Brasil teve uma economia crescendo para fora, isto $e$, inserindo-se cada vez mais no sistema internacional da divisão do trabalho e, conseqüentemente, ampliando as suas exportações. Nesses períodos, ao mesmo tempo em que as atividades ligadas ao mercado externo se expandiam, as voltadas para o atendimento da demanda interna comportavam-se inversamente ou, pelo menos, reduziam o seu ritmo de crescimento. 
Excetuados os períodos de total regressão às atividades de subsistência, tôda vez que, por diferentes razões, 0 setor de exportação enfrentou algum revés, a economia brasileira cresceu para dentro, isto é, voltou-se à produção de bens para 0 atendimento da demanda interna. Não foi nada além disso, o que ocorreu no Brasil a partir de 1929, quando - processo de substituição de importaçōes ganhou considerável impulso.

Entretanto, a partir do fim da segunda guerra, o sistema económico brasileiro ganhou gradativamente autonomia e complexidade, em relação ao resto do mundo. Quando, pelo menos em grande parte, foram eliminadas as dificuldades que se apresentavam ao setor exportador nacional, o setor interno, se ainda não ganhara fôlego suficiente para auto-sustentar-se no seu desenvolvimento, recebeu decidido apoio governamental, que the garantiu expandir-se a taxas bastante elevadas. ${ }^{12}$ Portanto, no último quarto do século, o conjunto da economia brasileira ganhou relativa autonomia em relação ao exterior, isto é, os reflexos das crises conjunturais externas na economia interna passaram a ser menos sensiveis. Por outro lado, na medida de sua maior complexidade, o sistema econômico nacional passou a gerar as suas próprias crises e contradições. ${ }^{13}$

Foi exatamente neste contexto que o Paraná passou a ganhar maior significado econômico dentro do país, pois foi a partir de 1945 que se transformou - ou de certa forma, especializou-se - no maior centro nacional de produção para o mercado externo, isto é, passou a crescer para fora. Os reflexos désse crescimento fizeram-se sentir particular-

12 Entre 1940 e 1950, o produto industrial brasilelro cresceu a uma taxa media anual de $7 \%$. Entro 1950 1961. essa taxa foi de cerca de $9 \%$, sendo que alcançou $11 \%$, entre 1956 - 1961.

13 A propósito ver: Singer, Paul. Decenvolvimento crise. Op. cit., cap. 4.

14 Ministério do Planejamento e Coordenaçăo Geral. A Industrializagăo brastleira: diagnostico popoctlvas. 1967, p. 173. mente na evolução demográfica e no aumento da renda interna do estado. Entretanto, no fim do decênio dos anos cinqüenta, a expansão física do setor exportador encontrava 0 seu limite. A partir dal, o crescimento da cafeicultura dependeria cada vez mais, dos aumentos de produtividade econômica, isto é, da melhor qualificação e não da maior quantidade dos arbustos.

Foi então que o estado tentou reproduzir o modélo de crescimento ocorrido no conjunto do país. Tendo-se manifestado algumas dificuldades - que foram diagnosticadas quase que de início - para o setor externo, os esforços governamentais se dirigiram em boa parte ao incentivo do setor industrial do estado, tentando fazer com que a economia local crescesse também para dentro.

Entretanto, como já se viu, a maior parte dos investimentos e dos incentivos ao setor industrial visaram às indústrias alimentícias, às de madeira e papel. Ocorre que, já em 1953, "a participação da produção interna na oferta total dos ramos tradicionais téxtil, alimentos, vestuário, bebidas, fumo, couros, peles e editorial gráfica variava entre 96 e 100 por cento, indicando que o processo de substituição de importações nessa área, acelerado no préguerra, encontrava-se já pràticamente concluido. 14 Por outro lado, "o ramo de papel e papelão apresentou $(.$. ) uma expansão de produção interna, concomitante com uma redução absoluta das importaçōes, sobretudo sensivel, a partir de 1959. Êste comportamento resultou no coeficiente produção nacional/oferta total que era de $80 \%$ em 1954 passou para $97 \%$ em 1963, ao mesmo tempo em que a participaçāo das importaçōes do papel e papelāo na pauta de importaçōes industriais caía de $4,3 \%$ em 1955 para 2,1\% em 1965. Este aumento da participaçăo da produção interna na oferta total foi desigualmente distribuido, (...) existindo ainda amplas margens de substituição de papel de imprensa, que representa atualmente cérca de $10 \%$ da oferta total do ramo". 15 
Portanto, pode-se dizer, à época em que o estado do Paraná ensaiou os primeiros passos a caminho da industrialização, o fêz tentando imitar ou seguir os caminhos percorridos pelo processo de industrialização nacional, isto é, através da substituição de importações. Entretanto, é de consenso geral que êsse processo pràticamente se esgotou no início da década de 1960, a partir de quando a taxa de crescimento da oferta dos produtos industriais declinou de forma permanente, pelo menos até fins de 1967 ou começos de 1968. Porém, no caso paranaense, o fenômeno ainda foi mais acentuado, pois a maior parte das indústrias instaladas era do ramo alimenticio, cujo mercado, como se viu, já há cêrca de quinze anos era suficientemente atendido pela produção nacional. Não é preciso buscar outra explicação para se compreender a razão pela qual várias das indústrias de óleos vegetais e frigorificas encerraram suas atividades pouco depois de iniciá-las. Em apoio do que se afirma, observa-se que diferentes foram os comportamentos das indústrias de café solúvel e de papel, instaladas no estado que, malgrado algumas dificuldades criadas por importadores estrangeiros (no caso do solúvel) conseguiram, não só manter-se, como prosperar.

$\mathrm{Na}$ verdade, a causa fundamental do relativo malógro de boa parte dos esforços industrializantes do Paraná foi o fato delas terem-se orientado no sentido substitutivo de importações, quando êsse processo já se havia, pràticamente, esgotado. Entretanto, esta não foi a única causa da considerável queda no ritmo de crescimento da economia estadual. Outras houve, como se verá em seguida.

2. Pari passu com a aceleração do processo substitutivo de importações, houve,

15 Ministério do Planejamento e Coordenaçăo Geral. A Industrializaçăo braslleira: diagnóstico perspectivas. 1967. p. 178.

16 Não existem informações fidedignas sơbre a real dimensão de desemprêgo provocado pela erradlcaçăo cafeeira. Há. entretanto, os que afirmam que o desemprégo atingiu cêrca de 10 mll familias, ou seja, $50 \mathrm{mil}$ pessoas, aproximadamente. no pais, especialmente durante a segunda metade do decênio dos cinquienta, um considerável aumento da rêde viária nacional, o que, em outros têrmos, redundou numa integração cada vez maior do mercado consumidor de manufaturas. A ligação muito mais rápida entre os mais distantes pontos do pais aproximou os centros produtores dos consumidores. $O$ efeito dêsse fenómeno é muito parecido com o da eliminação de barreiras alfandegárias à importaçāo. De fato, as grandes distâncias e a precariedade dos meíos e das vias de transporte funcionaram como elementos protetores às pequenas ou médias indústrias espalhadas pelo pais. Entretanto, à medida que essas dificuldades foram sendo eliminadas, as indústrias de alguns estados, que funcionavam em precárias condições tecnológicas, viram-se repentinamente diante da necessidade de enfrentar uma dura concorrência com indústrias localizadas na região centro-sul do pais. $E$ muitas delas, incapazes de superar as próprias deficiências, melhorando o padrão de qualidade dos seus produtos e reduzindo os custos de produção, sucumbiram. Será que é preciso buscar outras explicações para as dificuldades por que passaram as indústrias gaúchas, a indústria têxtil do vale do Itajaí, algumas de Minas Gerais? Ora, se isto é verdade para êsses estados, a fortiori, e com mais razão, o é para o Paraná. Localizado a pequena distância de São Paulo, passagem obrigatória para quem demanda os mercados dos outros dois estados sulinos $\theta$, pràticamente, sem nenhuma tradição industrial, é óbvio que teria maiores dificuldades em dinamizar seu parque industrial, ou seja, crescer para dentro.

3. Além disto, cabe referir que outros acontecimentos interferiram, negativamente, na economia estadual, na década dos sessenta. A politica de erradicação do café, adotada entre 1965 e 1967, determinou a desocupação de considerável contingente de mão-de-obra. ${ }^{16}$

Os efeitos negativos dessa política, para o Paraná, manifestaram-se em vários sen- 
tidos. A contração da renda interna pelo decréscimo da produção de café redundou necessàriamente na redução do poder aquisitivo global do estado. Por outro lado, a desocupação de mão-de-obra, gerando forte contingente de volantes, como se sabe, de rendimento baixo e irregular, provocou, ainda que em alguma medida, uma retração na demanda de certos bens. Poder-se-ia alegar aqui - e com alguma razão - que as terras liberadas pelo café erradicado foram de serventia para outras atividades da lavoura. Entretanto, embora isto tenha ocorrido, como a obrigatoriedade de utilização de terras, por essa forma, se limitava a dois anos, decorrido tal prazo, boa parte dessas áreas passou a ser utilizada para a pecuária. De qualquer forma, mesmo que năo se introduzisse a pecuária, ocorreria, como de fato ocorreu, uma demanda menor de mão-de-obra e, provàvelmente, uma redução na renda gerada.

Estes fenômenos se devem ao fato de que qualquer atividade agrícola carece de menor quantidade de mão-de-obra que a cafeicultura, porque exige menor número de pessoas para se desenvolver, ou porque, culturas temporárias que são, usam mão-de-obra por menor espaço de tempo, durante o ano. Há mesmo quem afirme que, "substituído o café por outras lavouras, mantidos os mesmos fatôres de produção, a renda gerada alcança ao máximo $70 \%$ da atingida pelo café. 17 Por mais discutivel que seja a porcentagem referida, não é fácil negar-se o fato em si, mesmo porque várias culturas - feijão, milho etc. eram feitas nas ruas do cafèzal. Portanto, os acréscimos de produção de bens de lavoura, criados pela reutilização das terras liberadas, não podem ser considerados, de forma absoluta, pois a erradicação do café significa também a erradicação dessas atividades complementares. Por outro lado, não se pode omitir o

17 Governo do Estado do Paraná. Análiee da conjuntura oconómica do Paraná. 1967. p. 7.

18 Secretaria da Agricultura do Estado de Săo Paulo. Necessidade da reformulaçăo da polítlca braslieira do cafó. 1970 (exemplo datilografado). p. 1-3. fato, não menos importante, de que ao substituirem-se algumas atividades mais intensamente utilizadoras de mão-de-obra por outras, de utilização menor, ocorre fatalmente o fenômeno da concentração de renda que raramente é benéfico à economia. Portanto, mesmo em parcela de dimensões discutiveis, a erradicação do café, para a economia paranaense, não foi benéfica, uma vez que contribuindo à limitação da demanda de bens industrializados, conseqüentemente, se constituiu num fator a mais, de ação adversa aos esforços de industrialização.

Não se quer aqui ampliar o debate a respeito de problema da erradicação do café e nem da situação do mercado internacional dêsse produto. Entretanto, a posição brasileira, nesse mercado, nāo é das mais lisonjeiras. A última conferéncia da Organização Internacional do Café (agôsto de 1970) foi suficiente para mostrar que o Brasil perdeu parte de sua fôrça atuante, diante de concorrentes igualmente capazes de lutar pelos próprios interêsses. Por outro lado, o problema da adequação da oferta désse produto à sua demanda ainda não encontrou solução adequada, pelo menos em nosso país. Como se sabe, através do Acórdo Internacional do Café são fixadas quotas de exportação aos paises produtores. 0 Brasil, nos últimos oito anos - com exceção de um, e de 1965/66 - tem obtido safras insuficientes para atender os seus compromissos com o exterior e o consumo interno. Por êsse motivo, vem recorrendo, sistemáticamente, aos estoques acumulados. 18 Mas, se por um lado, isto apresenta aspectos positivos, pois significa um menor esfórço da economia do país na imobilização de recursos para aquisição dos excedentes, e de outro, traz, pelo menos, apreensões quanto ao futuro, pois poderão ocorrer dificuldades da oferta no atendimento da demanda.

Conscientes dessa realidade, os governos da União e do estado de São Paulo estão hoje envidando esforços consideráveis, no incentivo à formação de novos cafèzais, que au- 
mentem a nossa produção, fazendo-a estabilizar-se em tôrno dos 30 milhões de sacas por ano.

Que a consecução dêsse intento não é tarefa fácil, é claro, pois o café é uma atividade agrícola em extrema dependência das condições climáticas e qualidade do solo. Assim é que, para uma estabilidade maior, no tocante às quantidades produzidas, é necessário que os cafèzais se localizem em áreas pouco sujeitas às geadas e cujo solos sejam de boa qualidade. Diante disso, o estado de São Paulo apresenta melhores condições que - Paraná, sujeito êste último periodicamente, à ação de intensas geadas, e se ressentindo de um decréscimo na fertilidade dos solos das áreas situadas além de Maringá. Como se não bastasse isso, no estado de São Paulo, nos últimos oito anos, foram replantados nada menos que 113 milhões de arbustos, em áreas favoráveis ao desenvolvimento das culturas e em condições técnicas bastante superiores àquelas do Paraná. 19

Embora a ferrugem esteja a determinar a necessidade de novos estudos, que permitam a descoberta de espécies mais resistentes à praga e, conseqüentemente, possam retardar 0 replantio, há que pensar-se sèriamente em como se fazer para que o Paraná não se veja surpreendido pela perda de parte considerável da sua principal atividade geradora de renda e de emprêgo. Se isto ocorrer - isto é, se a cafeicultura voltar para São Paulo a situação da economia do estado poderá tornar-se verdadeiramente crítica.

Do que se disse, entretanto, não se conclua que o Paraná é hoje um estado sem perspectivas econômicas.

No que concerne ao café, que se tome consciência de que defendendo-se a sua produção e a sua posição de principal produtor, estar-se-á, ipso facto, fazendo avultar a maior parte da renda e volume do emprêgo. É pre-

19 Secretaria da Agricultura do Estado de São Paulo. Estudo para um programa de reorganizaçăo da cafelcultura do estado de Săo Paulo. 1970. p. 4, mimeogr. ciso que se cuide eficazmente da renovação dos cafèzais, tornando-os ainda mais rentáveis $e$ incentivando sua implantação nas áreas menos sensíveis aos efeitos meteorológicos e de solos mais propicios a essa cultura. E indiscutivel, então, que os cafezzais paranaenses devam voltar para as áreas do norte velho e do horto nóvo, isto é, desde Jacarèzinho até Maringá.

Quanto ao setor industrial, existem perspectivas para o estado, em alguns ramos. A política econômica do govêrno da União, no que se refere ao setor industrial, é nitida: há evidente esfórço no sentido de se fortalecerem os chamados setores dinâmicos: a indústria petroquímica, elétrica e eletrônica, automobilística e de construção civil. Na elétrica e eletrônica, bem como na automobilística, as perspectivas paranaenses não parecem existir, pelo menos a curto e médio prazos. 0 mesmo, entretanto, não se dá com a indústria petroquímica, de construção civil (incluindo transformação de minerais não metálicos) $\theta$ a de papel, principalmente o de imprensa, em que as perspectivas são animadoras.

As jazidas de xisto pirobetuminoso de que o estado é detentor garantem uma sólida indústria no ramo. E a sua reserva florestal embora já pequena - aliada a uma forte política de reflorestamento, poderá garantir-lhe uma situação privilegiada, enquanto produtor de certos tipos de papel de que o mercado nacional é carente. $E$ a indústria de construção civil, com a complementar, de transformação de minerais não metálicos, poderá ser desenvolvida consideràvelmente, pois ainda grande parte das moradas, no estado, são de construção precária. Além disso, dependendo, evidentemente, do comportamento do mercado externo, a indústria do café solúvel poderá tornar-se bastante importante na economia estadual.

O que parece, entretanto, claro é que o Paraná não tem ainda condições de deixar de ser um estado fortemente dependente do setor primário. Se isto é verdade, tem que ativar esforços e alocar recursos, no sentido de tor- 
nar-se um proautor de bens agropecuários de alta qualidade, para se impor no mercado consumidor, interno e externo. Mas, mesmo que se desenvolvam as atividades do setor secundário a que se têz referência e que a agro- pecuária do estado venha a tornar-se das mais eficientes do país, ainda assim, muitos anos decorrerão até que o Paraná deixe de ser umá economia periférica e subsidiária do centro dinâmico do país.

\begin{tabular}{|c|c|c|c|c|c|c|c|}
\hline Ano & Total & Comérclo & $\begin{array}{l}\text { Intermed. } \\
\text { flnancelros }\end{array}$ & $\begin{array}{l}\text { Transp. } \\
\text { Comunic. }\end{array}$ & Governo & Alugueís & $\begin{array}{l}\text { Outros } \\
\text { Serviços }\end{array}$ \\
\hline $\begin{array}{l}1939 \\
1947 \\
1948 \\
1949 \\
1950 \\
1951 \\
1952 \\
1953 \\
1954 \\
1955 \\
1956 \\
1957 \\
1958 \\
1959 \\
1960 \\
1961 \\
1962 \\
1963 \\
1964 \\
1965 \\
1966\end{array}$ & $\begin{array}{c}44,7 \\
100 \% \\
2.135,3 \\
100 \% \\
2.607,1 \\
100 \% \\
3.185,5 \\
100 \% \\
4.050,7 \\
100 \% \\
4.986,8 \\
100 \% \\
6.415,0 \\
100 \% \\
7.760,7 \\
100 \% \\
9.266,2 \\
100 \% \\
13.140,6 \\
100 \% \\
16.235,1 \\
100 \% \\
21.070,3 \\
100 \% \\
26.834,7 \\
100 \% \\
36.198,5 \\
100 \% \\
52.086,1 \\
100 \% \\
79.380,7 \\
100 \% \\
130.515,6 \\
100 \% \\
229.953,9 \\
100 \% \\
449.053,7 \\
100 \% \\
782.093,8 \\
100 \% \\
1.225 .815,5 \\
100 \% \\
1.726 .992,7 \\
100 \%\end{array}$ & $\begin{array}{c}159,2 \\
35,8 \% \\
855,9 \\
40,1 \% \\
1.075,2 \\
41,3 \% \\
1.320,9 \\
41,5 \% \\
1.715,3 \\
42,3 \% \\
1.994,0 \\
40,0 \% \\
2.529,1 \\
39,4 \% \\
2.765,6 \\
35,6 \% \\
2.965,4 \\
32,0 \% \\
4.731,9 \\
36,0 \% \\
3.934,7 \\
24,2 \% \\
5.471,7 \\
25,2 \% \\
7.393,9 \\
27,5 \% \\
11.733,5 \\
32,4 \% \\
15.083,9 \\
28,8 \% \\
19.920,3 \\
25,1 \% \\
34.026,2 \\
26,1 \% \\
49.699,5 \\
21,6 \% \\
85.596,7 \\
19,1 \% \\
155.421,0 \\
18,9 \% \\
175.167,2 \\
14,3 \% \\
246.829,8 \\
14,3 \% \\
\end{array}$ & $\begin{array}{c}25,5 \\
5,7 \% \\
168,5 \\
7,8 \% \\
201,4 \\
7,8 \% \\
264,0 \\
8,3 \% \\
367,5 \\
9,1 \% \\
511,9 \\
10,3 \% \\
657,9 \\
10,2 \% \\
928,2 \\
12,0 \% \\
1.171,9 \\
12,6 \% \\
1.501,0 \\
11,4 \% \\
1.767,1 \\
10,9 \% \\
2.681,8 \\
12,3 \% \\
3.613,7 \\
13,5 \% \\
4.616,7 \\
12,7 \% \\
6.902,0 \\
13,2 \% \\
9.972,9 \\
12,6 \% \\
17.231,7 \\
13,2 \% \\
32.745,9 \\
14,3 \% \\
65.908,3 \\
14,7 \% \\
119.096,5 \\
15,2 \% \\
294.177,5 \\
24,0 \% \\
406.728,1 \\
23,5 \%\end{array}$ & $\begin{array}{c}67,5 \\
15,2 \% \\
275,0 \\
12,9 \% \\
337,8 \\
12,9 \% \\
433,0 \\
13,6 \% \\
489,7 \\
12,1 \% \\
619,0 \\
12,4 \% \\
810,4 \\
12,6 \% \\
1.016,5 \\
13,1 \% \\
1.049,9 \\
11,3 \% \\
1.501,0 \\
11,4 \% \\
2.691,9 \\
16,6 \% \\
3.136,1 \\
14,4 \% \\
3.709,3 \\
13,8 \% \\
4.287,0 \\
11,8 \% \\
7.293,5 \\
14,0 \% \\
12.484,7 \\
15,7 \% \\
18.083,2 \\
13,8 \% \\
33.926,9 \\
14,7 \% \\
63.990,8 \\
14,2 \% \\
106.090,8 \\
13,6 \% \\
152.245,0 \\
12,4 \% \\
223.282,3 \\
12,9 \% \\
\end{array}$ & $\begin{array}{c}74,1 \\
16,7 \% \\
307,4 \\
14,4 \% \\
337,8 \\
12,9 \% \\
400,3 \\
12,6 \% \\
493,3 \\
12,2 \% \\
679,7 \\
13,6 \% \\
836,0 \\
13,0 \% \\
1.031,6 \\
13,3 \% \\
1.162,8 \\
12,5 \% \\
1.544,2 \\
11,7 \% \\
2.727,1 \\
16,8 \% \\
3.179,0 \\
14,6 \% \\
3.714,1 \\
13,8 \% \\
5.002,7 \\
13,8 \% \\
6.362,9 \\
12,4 \% \\
11.660,1 \\
14,7 \% \\
20.181,8 \\
15,5 \% \\
35.306,8 \\
15,3 \% \\
65.350,8 \\
14,5 \% \\
113.631,3 \\
14,5 \% \\
177.033,6 \\
14,4 \% \\
240.324,0 \\
13,9 \% \\
\end{array}$ & $\begin{array}{c}21,0 \\
4,7 \% \\
73,3 \\
3,4 \% \\
145,9 \\
5,6 \% \\
184,4 \\
5,8 \% \\
252,3 \\
6,3 \% \\
225,5 \\
4,5 \% \\
329,3 \\
5,1 \% \\
500,6 \\
6,4 \% \\
623,0 \\
6,7 \% \\
851,5 \\
6,5 \% \\
978,3 \\
6,0 \% \\
1.297,5 \\
6,0 \% \\
1.511,0 \\
5,6 \% \\
1.714,4 \\
4,7 \% \\
2.083,3 \\
4,0 \% \\
2.162,8 \\
2,7 \% \\
3.190,0 \\
2,4 \% \\
7.481,1 \\
3,3 \% \\
18.761,6 \\
4,2 \% \\
25.306,5 \\
3,2 \% \\
32.858,9 \\
2,7 \% \\
49.943,0 \\
2,9 \%\end{array}$ & $\begin{array}{r}97,4 \\
21,9 \% \\
455,2 \\
21,3 \% \\
509,1 \\
19,5 \% \\
582,4 \\
18,2 \% \\
732,6 \\
18,0 \% \\
956,7 \\
19,2 \% \\
1.262,3 \\
19,7 \% \\
1.518,0 \\
19,6 \% \\
2.293,2 \\
24,7 \% \\
3.011,0 \\
22,9 \% \\
4.136,0 \\
25,5 \% \\
5.304,2 \\
27,5 \% \\
6.912,7 \\
25,8 \% \\
8.844,2 \\
24,6 \% \\
14.260,5 \\
27,5 \% \\
23.179,9 \\
29,2 \% \\
37.802,7 \\
29,0 \% \\
70.793,7 \\
30,8 \% \\
149.445,4 \\
33,3 \% \\
262.547,7 \\
33,6 \% \\
394.433,3 \\
32,2 \% \\
559.885,5 \\
32,5 \%\end{array}$ \\
\hline
\end{tabular}

Fonte dos dados brutos: Conjuntura económica, jun. 1970. 
Anexo 2. Produto Real (a preços de 1949). Em Cr\$ 1.000

$\begin{array}{ccrc}\text { Ano } & \text { Brasil } & \text { Paraná } & \begin{array}{c}\text { PR/BR } \\ \%\end{array} \\ 1947 & 157.222,6 & 5.685,0 & 3,62 \\ 1948 & 172.126,9 & 6.690,0 & 3,89 \\ 1949 & 181.760,2 & 7.619,6 & 4,19 \\ 1950 & 190.848,2 & 8.754,9 & 4,59 \\ 1951 & 200.663,3 & 9.164,9 & 4,57 \\ 1952 & 211.932,4 & 11.254,1 & 5,31 \\ 1953 & 218.557,5 & 11.011,1 & 5,04 \\ 1954 & 235.581,2 & 10.748,2 & 4,56 \\ 1955 & 251.556,1 & 15.828,2 & 6,29 \\ 1956 & 256.281,9 & 13.962,2 & 5,45 \\ 1957 & 273.912,6 & 15.595,8 & 5,69 \\ 1958 & 292.088,6 & 19.832,3 & 6,79 \\ 1959 & 333.348,2 & 36.075,8 & 10,82 \\ 1960 & 313.536,3 & 34.169,3 & 10,90\end{array}$

Fonte: Revista brasllelra de economla, mar. e set. de 1962.

Anexo 3. Fenda Interna 1939/1967. Em Cr\$ 1.000

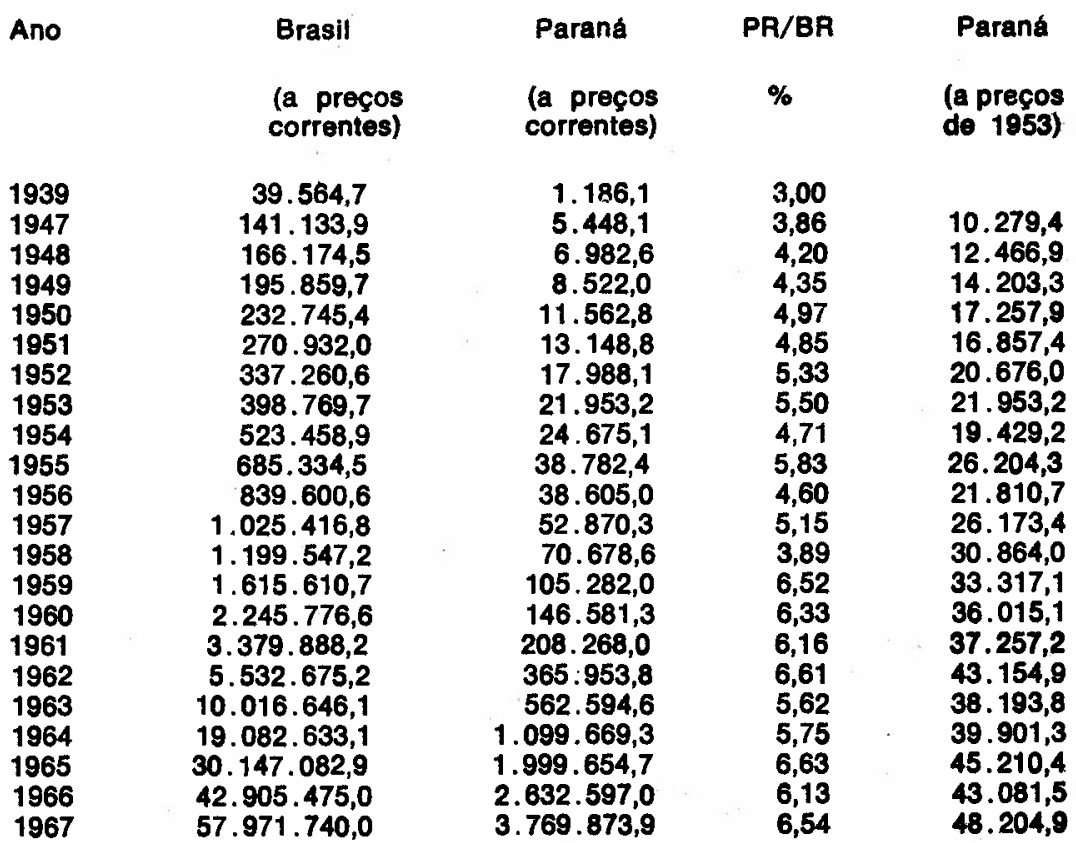

Fonte: Fundação Getúlio Vargas. Conjuntura económica, jun./70

Obs.: Foi usado como defistor, o indice económico n.० 2 (preços) calculado pela FGV e publicado na revista Conjuntura Económica. 


\begin{tabular}{|c|c|c|c|c|c|c|c|}
\hline Ano & Agricultura & $\%$ & Indústria & $\%$ & Serviços & $\%$ & Total \\
\hline $\begin{array}{l}1939 \\
1947 \\
1948 \\
1949 \\
1950 \\
1951 \\
1952 \\
1953 \\
1954 \\
1955 \\
1956 \\
1957 \\
1958 \\
1959 \\
1960 \\
1961 \\
1962 \\
1963 \\
1964 \\
1965 \\
1966 \\
1967\end{array}$ & $\begin{array}{r}575 \\
2.605 \\
3.404 \\
4.055 \\
5.967 \\
6.473 \\
9.382 \\
11.620 \\
11.931 \\
21.366 \\
17.165 \\
25.757 \\
36.676 \\
58.050 \\
80.541 \\
110.011 \\
202.462 \\
263.087 \\
514.735 \\
1.018 .512 \\
1.085 .575 \\
1.683 .524\end{array}$ & $\begin{array}{l}48,5 \\
47,8 \\
48,7 \\
47,6 \\
51,6 \\
49,2 \\
52,2 \\
52,9 \\
48,3 \\
55,1 \\
44,5 \\
48,7 \\
51,9 \\
55,1 \\
54,9 \\
52,8 \\
55,3 \\
46,8 \\
46,9 \\
50,9 \\
41,2 \\
44,2\end{array}$ & $\begin{array}{r}166 \\
708 \\
971 \\
1.282 \\
1.545 \\
1.689 \\
2.191 \\
2.573 \\
3.478 \\
4.275 \\
5.205 \\
6.043 \\
7.148 \\
11.033 \\
13.954 \\
18.876 \\
32.976 \\
69.534 \\
132.880 \\
199.049 \\
321.106 \\
379.357\end{array}$ & $\begin{array}{r}14,0 \\
13,0 \\
13,9 \\
15,0 \\
13,4 \\
12,8 \\
12,2 \\
11,7 \\
14,1 \\
11,0 \\
13,5 \\
11,4 \\
10,1 \\
10,5 \\
9,5 \\
9,1 \\
9,0 \\
12,4 \\
12,1 \\
9,9 \\
12,2 \\
10,0\end{array}$ & $\begin{array}{r}445 \\
2.135 \\
2.607 \\
3.185 \\
4.051 \\
4.969 \\
6.415 \\
7.761 \\
9.266 \\
13.141 \\
16.235 \\
21.070 \\
26.855 \\
36.198 \\
52.086 \\
79.381 \\
130.516 \\
229.954 \\
449.054 \\
782.094 \\
.225 .915 \\
1.726 .993\end{array}$ & $\begin{array}{l}37,5 \\
39,2 \\
37,4 \\
37,4 \\
35,0 \\
38,6 \\
35,6 \\
35,4 \\
37,6 \\
33,9 \\
42,0 \\
39,9 \\
38,0 \\
34,4 \\
35,5 \\
38,1 \\
35,7 \\
40,9 \\
41,0 \\
39,2 \\
46,6 \\
45,8\end{array}$ & $\begin{array}{r}1.186 \\
5.448 \\
6.983 \\
8.522 \\
11.563 \\
13.149 \\
17.988 \\
21.953 \\
24.675 \\
28.782 \\
38.603 \\
52.870 \\
70.679 \\
105.282 \\
146.581 \\
208.268 \\
365.954 \\
562.595 \\
1.096 .669 \\
1.999 .655 \\
2.632 .597 \\
3.789 .874\end{array}$ \\
\hline
\end{tabular}

Fonte: Conjuntura economica, jun., 1970

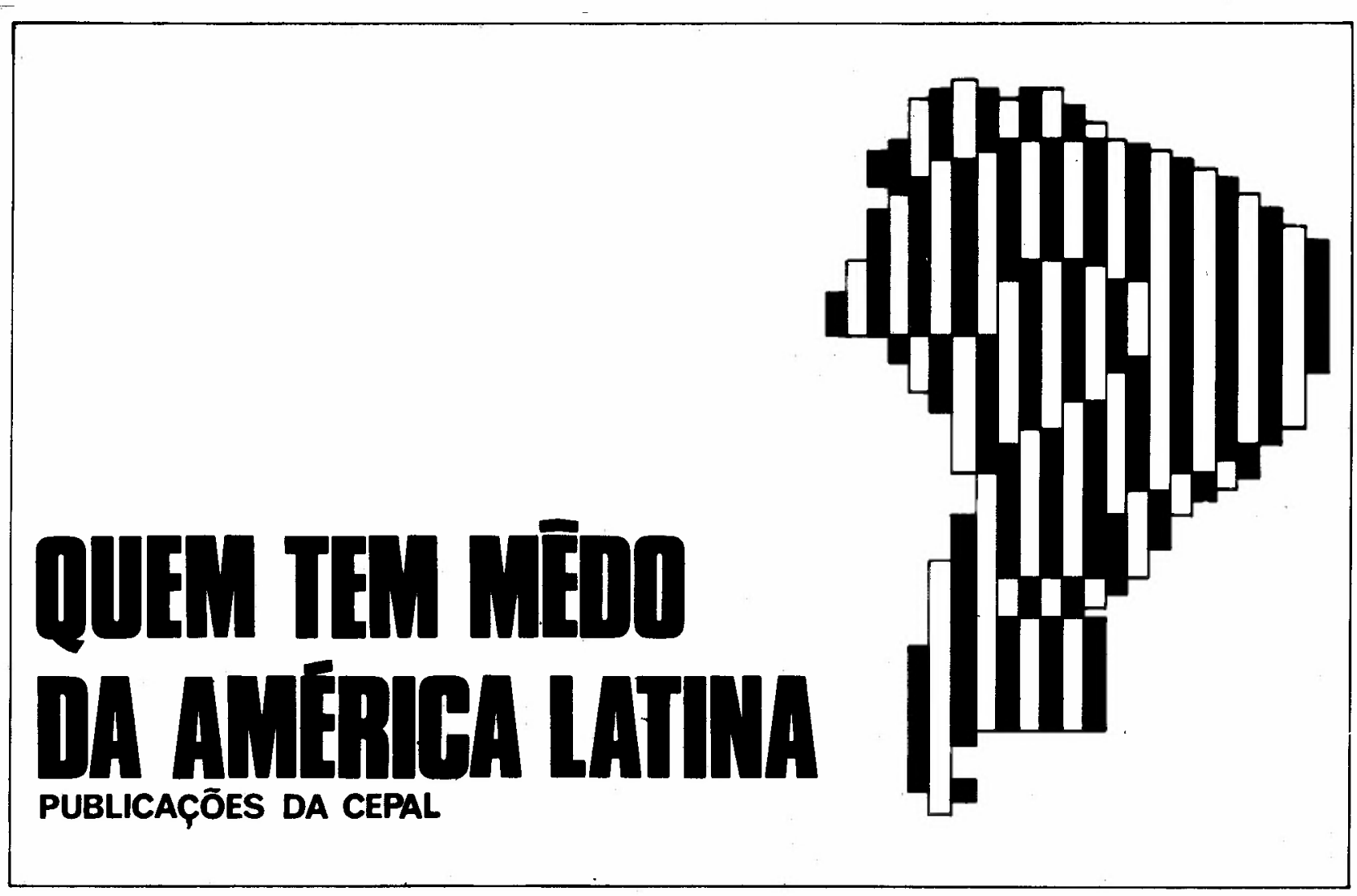

